\title{
Bazı Tarla Bitkilerinin Tuz Stresine Gösterdikleri Adaptasyon Mekanizmaları
}

\section{İskender TİRYAKI}

Çanakkale Onsekiz Mart Üniv., Ziraat Fak. Tarımsal Biyoteknoloji Böl. Çanakkale

$\triangle$ : itiryaki@comu.edu.tr

\section{ÖZET}

Topraklardaki tuzluluk dünya genelinde bitkisel üretimde verimi doğrudan sinırlandıran en önemli abiyotik stress faktörlerinden biridir. Tuz stresi aynı zamanda tarımsal üretimin yapıldığı bölgelerde bitkisel çeşitliliği doğrudan belirler niteliktedir. Tuz stresine karşı bitkisel tepkilerin oluşması ve ortaya çıkması, kompleks moleküler mekanizmalar tarafindan kontrol edilen fizyolojik değişimlere neden olmakta ve devamında tolerans gelişmektedir. Bu değişim ve farklılıklar bazen bitki türüne özgü bazen de tüm bitkilerde ortak olarak ortaya çıkabilen benzer mekanizmalar ile tanımlanabilmektedir. Kompleks olan bu mekanizmalar aynı zamanda doğrudan tuz stresine yönelik olarak gelişebileceği gibi bazı durumlarda kuraklık gibi diğer abiyotik stress faktörleri ve hatta biyotik stress faktörleri ile birlikte ortaklaşa kullanılan mekanizmalara bağlı olarak gelişebilmektedir. $\mathrm{Bu}$ nedenle gerek bitki düzeyinde gerekse tolerans mekanizmaları seviyesinde bitkilerdeki tuz stresi ve tolerans mekanizmalarının anlaşılması, tuz stresini daha iyi tolere edebilen yeni bitki çeşitlerinin geliştirilmesine çok önemli katkılar sunacaktır. Bu çalışma, güncel literatür varlığında tuz stresine yönelik bitkisel tepkilerin anlaşılmasına katkı sunmak amacıyla hazırlanmıştır.

\section{Adaptation Mechanisms of Some Field Plants Against to Salt Stress}

\section{ABSTRACT}

Soil salinity is one of the most important abiotic stress factors which directly limits plant yield in agricultural production areas around the World. Salt stress also determines plant diversity in agricultural production areas. Development and revealing of plant response against to salt stress depends on physiological changes of plants controlled by complex molecular mechanisms which subsequently lead to development of tolerance. Sometimes, such changes and differences appear to be unique to the type of plant, but some other times, such responses are more common and similar in all plants. In addition, although such complex mechanisms appear to be developed directly related to salt stress per se, they may also be the results of other abiotic stress, like drought, or even biotic stress related responses. Therefore, better understanding of salt tolerance at both plant and mechanism levels will make significant contribution to develop better salt tolerant new plant varieties. The aim of this review was to make contribution on understanding of plant response against to salt stress based on current literature.
DOI:10.18016/ksudobil.325374

\author{
Makale Tarihçesi \\ Received : 01.07.2017 \\ Accepted : 09.04.2018
}

Anahtar Kelimeler
Tuz,
stres,
tolerans

\section{Derleme Makale}

\author{
Article History \\ Received : 01.07.2017 \\ Accepted : 09.04.2018
}

Keywords
Salt,
stress,
tolerance.

\section{Review Article}

To cite : Tiryaki İ 2018. Bazı Tarla Bitkilerinin Tuz Stresine Gösterdikleri Adaptasyon Mekanzimaları. KSÜ Tarim ve Doğa Derg 21(5):800-808, DOI:10.18016/ksudobil.325374

\section{TUZ STRESI}

Tuz, kuraklık ile birlikte günümüzde ve yakın gelecekte bitkisel üretim ve verimliliği doğrudan etkileyen en önemli stres faktörlerinden biridir (Parida ve Das, 2005). Dünya genelinde tarımı yapılan alanların hali hazırda \%20'sinin, 2050 yılına kadar ise \%50'sinin tuzluluk sorunu ile karşı karşıya kalacağı tahmin edilmektedir (Kang ve ark., 2010). Tuzluluk, dünyada olduğu gibi ülkemizde de bitki çeşitliliğini ve tarımsal üretkenliği azaltan önemli sorunlardan birisidir. Özellikle kurak ve yarı kurak iklim bölgelerinde yetersiz yağış ve yüksek buharlaşma, 
drenaj yetersizliği, yanlış tarımsal uygulamalar ve toprak özellikleri tuzluluğun başta gelen sebeplerinden olup geniş alanları etkilemektedir (Anonim, 2005). Türkiye'de 1.518.722 ha alanda tuzluluk ve alkalilik (çoraklık) sorunu olduğu, bu alanın ülkemiz yüzölçümünün \% 2'sini, toplam işlenen arazilerin ise \% 5.48'ini oluşturduğu rapor edilmiştir (Temel ve Şimşek, 2011). Bir yörede gerekli tedbirler alınmasına rağmen toprak tuzluluğunun kontrolü mümkün olmuyorsa, o yörede ortaya çıan tuzluluk düzeyinde gelişim gösterebilecek ve ekonomik verim sağlayabilecek tuza toleransı yüksek bitkilerin yetiştirilmesi (özellikle de yem bitkileri) suretiyle hem topraktaki organik madde miktarının artırılması hem de buharlaşma ile su kaybının (evaporasyon) azaltılması gerekmektedir (Anonim, 2005). Tuz, bitkilerde çoklu (pleitropik) etki yaratmakla birlikte, tuza tolerant bitkiler anotomik, biyokimyasal ve moleküler seviyede birçok farklılıklar sergileyebilmektedir (Pastori ve Foyer, 2002; Bartels ve Sunkar, 2005).

Tuz stresine yönelik çalışmalarda genellikle birbirlerinin yerine kullanılan fakat birbirinden farklı olan iki temel kavram bulunmaktadır. Bunlardan biri tuz stresi diğeri ise tuz şokudur. Tuz stresi, bitkilerin $\mathrm{NaCI}$ ile karşı karşıya kalması durumundaki tepkilerini ifade etmekte ve iki farkl formda ortaya çıkabilmektedir. Bunlardan birincisi bitkilerin tedricen artan tuz konsantrasyonu ile muamele edilmesi, ikincisi ise bitkilerin düşük bir tuz konsantrasyonu ile karşı karşıya bırakılması ya da bu iki uygulamanı birlikte uygulanmasını kapsamaktadır (Shavrukov, 2013). Buna karşılık tuz şoku, bitkilerin yüksek tuz konsantrasyonu ile anlık ve ani bir şekilde karşı karşıya kalmasını ifade etmektedir (Shavrukov, 2013). Tarım alanlarında tuz şoku daha nadir olarak görülürken, tuz stresi zaman içerisinde ortaya çıkmakta ve etkisini giderek artırmaktadır. Tuz stresi çalışmalarında bitkilere $\mathrm{NaCI}$ ya da deniz suyu genelde kontrollü laboratuvar ya da sera şartlarında uygulanmaktadır (Shavrukov, 2013). Tuz stresi çalışmaları, çalışılan bitki türü, çalışma amacı ve araştırıcının kendi tercihi gibi birçok faktöre bağlı olarak farklılıklar göstermektedir. Fakat bu çalışmalarda en belirleyici ve önemli olan nokta tuzun bitkilere nasıl uygulandığıdır. Bitkilere tuz stresi uygulamalarında genelde artan konsantrasyonlardaki NaCI (genelde 25 ya da $50 \mathrm{mM}$ artan konsantrasyonlarda), günlük olarak, daha önceden belirlenen maximum $\mathrm{NaCI}$ konsantrasyonuna ulaşıncaya kadar uygulanmaktadır (Shavrukov, 2013). Buna karşılık, tuz şoku uygulamalarında bitkiler $\mathrm{NaCI}$ olmayan normal büyüme ortamlarından alınarak yüksek NaCI konsantrasyonu bulunan büyüme ortamlarına transfer edilmekte ve belirlenen sürede tuz stresine maruz birakılmaktadır (Munns ve Tester, 2008; Shavrukov, 2013).
Ölümcül olmayan tuz konsantrasyonlarında tuz stresine toleranslı ve toleransl olmayan bitkilerin büyüme parametrelerinde gösterdikleri farklılıkların bazı bitki türlerinde çimlenme ve erken fide döneminde daha iyi bir şekilde belirlenebildiği rapor edilmiştir (Munns ve Gilliham, 2015; Munns ve Tester, 2008). Diğer taraftan bazı bitki türlerinde tuz stresi karşısında sodyum toksitesi belirtisi göstermemesine rağmen, bazı büyüme parametelerinde önemli farklılıklar meydana gelebilmektedir. Örneğin Arabidopsis bitkisinde tuz stresi karşısında yüksek hassasiyet gösteren mutant bitkilerin kök ve yaprak büyümelerinde 20 kattan daha fazla oranda gerileme meydana geldiği, ancak bitkilerin diğer bitkisel özellikler bakımından herhangi bir farklılık göstermedikleri tespit edilmiştir (Wu ve ark., 1996). Ayrıca aynı çalışmada büyümede görülen gerilemenin sodyum iyonlarının hücre içine geçişinden ziyade potasyum iyonlarının birikiminden kaynaklandığı belirlenmiştir. Mısır bitkisinde yapılan bir çalışmada ise tuz stresinin 5 saat ve 9 gün uygulanması durumunda genotipler arasında çok önemli farkların meydana geldiği, ancak erken büyüme döneminde tuz stresine karşı daha hassas olan bitkilerde sodyum iyonu birikiminin daha az oranda gerçekleştiği belirlenmiştir (Cramer ve ark., 1994). Farklı misır bitkilerinin tuz stresine verdikleri tepkilerin belirlendiği bir çalışmada ise kök ve yapraklarda genotipler arasında erken büyüme döneminde görülen farklılıkların normal büyüme sıcaklıklarında ilk 24 saat içerisinde ortaya çıtığını göstermiştir (Mladenova, 1990). Bu yüzden bitki genotplerinin kendilerine özgü olarak hızlı bir şekilde geliştirdikleri tuz stresi tepkilerinin yapraklarda biriken tuz birikimi ile birlikte NaCl'a verdikleri farklı tepkilerden kaynaklandığı belirtilmektedir (Chazen ve ark., 1995). Çeltikte yapılan bir çalışma, erken fide döneminde 10 gün süre ile yapılan tuz stresi uygulamasının bitkilerin sonraki büyüme dönemlerinde ve verimde çok önemli gerilemelere neden olduğunu göstermiştir (Aslam ve ark., 1993). Tüm bu çalışmalar, tuza karşı tolerans geliştiren bitkilerde yaprak büyümelerinin önemli oranda azaltıldığı ve tolerans düzeyinin genotip bazında morfolojik farklılıkların belirlenmesi yolu ile rahatlıkla tespit edilebileceğini göstermektedir. Bitkiler birçok stres faktöründe olduğu gibi tuz stresine karşı çimlenme ve erken fide dönemleri ile olgun bitki dönemlerinde farklı seviyelerde tepki/tolerans gösterebilmektedir. $\mathrm{Bu}$ nedenle, bitkilerin tuz stresine verdikleri tepkilerin farklı bitki gelişim evrelerinde test edilmesi gerekmektedir (Platten ve ark., 2006; Platten ve ark., 2013).

\section{ADAPTASYON MEKANIZMALARI}

Biyokimyasal

Bitkilerde tuz stresinin, doyurulmuş toprak 
ekstraktındaki elektrik iletkenlik değerinin 4.0 deciSiemens/metre (dS/m; yaklaşık $40 \mathrm{mM} \mathrm{NaCl}$ ) olması durumunda ortaya çıktığı, ancak bu değerlerin bitki türüne göre büyük farkllllıklar gösterdiği bilinmektedir (Onaga ve Wydra, 2016). Örneğin, çeltikte bu değer 3.0 $\mathrm{dS} / \mathrm{m}$ olarak belirlenmiştir (Volkov ve Amtmann, 2006). Bu sınır değerler dışında her-bir $\mathrm{dS} / \mathrm{m}$ için verimde \%12'lik azalış olduğu belirtilmiştir. Bitkiler tuzu tedricen biriktirdiklerinde ozmotik ve oksidatif stres ile birlikte besin elementi dengesizliği ile karşı karşıya kalmaktadır (Onaga ve Wydra, 2016). Karşılaşlan bu durum hücre içi iyon dengesi, membran fonksiyonları ve metabolik aktiviteleri doğrudan etkilenmektedir (Hasegawa ve ark., 2000; Volkov, 2015). Bu nedenle bitkiler tuz stresi ile karşı kaşıya kaldıklarında moleküler, biyokimyasal ve fizyolojik seviyede kompleks tepkiler göstermektedir (Şekil 1). Bu tepkilerin başında tuz stresinin bitki kökleri tarafindan algılanmasından sonra ortaya çıkan transkripsiyonel seviyedeki gen ifadelerinin kontrolünde gelişen fizyolojik ve biyokimyasal tepkiler gelmektedir. Tuz stresine karşı bitkiler tarafindan geliştirilen fizyolojik ve biyokimyasal tepkiler, tuz stresi ile ilişkili çok sayıdaki gene ait ifade (transkripsiyonel) farklılıklarının bir sonucu olarak ortaya çıkmaktadır. Diğer bir ifade ile bitkilerde tuz stresi karşısında tespit edilecek morfolojik, fizyolojik ve biyokimyasal değişimler, bir neden değil bir sonuçtur.

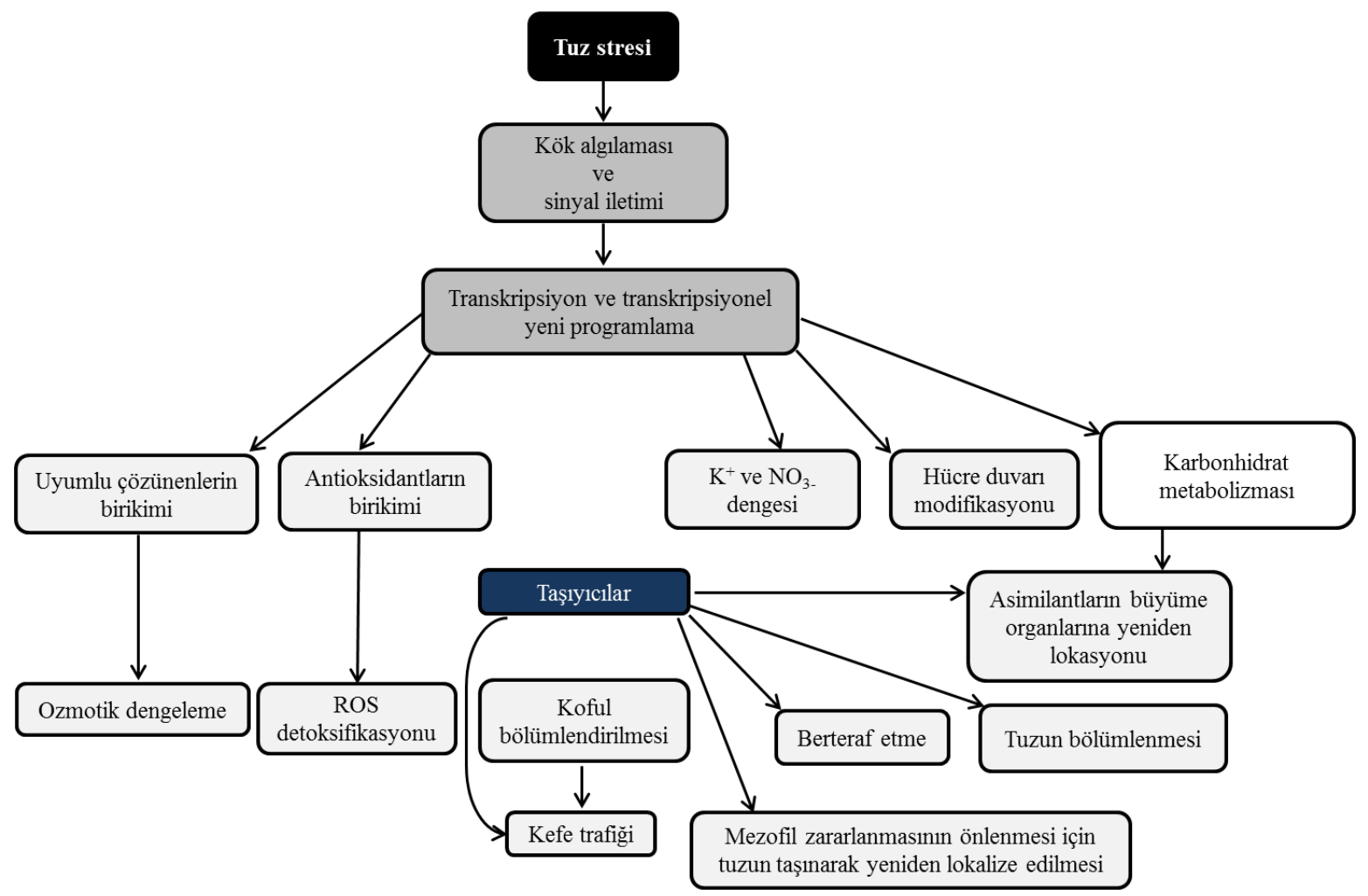

Şekil 1. Tuz stresine karşı bitkisel toleransın oluşmasında ortaya çıkan adaptasyon mekanizmaları. Tuz stresinin bitki kökleri tarafından algılanması ve buna yönelik sinyal iletimlerinin oluşması, gen ifade seviyesinde (transkripsiyonel) değişimler ve yeni gen ifade programlarının oluşması. Gen ifade seviyesinde oluşan farklılıklar ve yeni programlar bitkide farklı biyokimyasal ürünlerin sentezini ve devamında tuza toleranslığın ortaya çıkmasına sağlamaktadır (Munns ve Gilliham, 2015; Onaga ve Wydra, 2016).

Diğer taraftan halofit bir bitki olan Atriplex spongeosa ile fasulye ve bezelye bitkilerinin NaCI'e karşı eşit oranda duyarlılık gösterdiği tespit edilmiştir (Ouyang ve ark., 2010). Bunun nedeni, $100 \mathrm{mM}$ '’n üzerindeki tuz konsantrasyonlarında enzimlerin $\mathrm{Na}+$ iyonları tarafindan engellendiği gerçeğidir. $\mathrm{Bu}$ nedenle bitkilerde tuza tolerans mekanizması iki ana katogoriye bölünebilmektedir: (I) bitki dokuları tarafindan alınacak tuz miktarının engellenmesi ya da azaltılması ve (II) stoplazma içerisindeki tuz konsantrasyonunun azaltılması. Halofit bitkilerde her iki mekanizmanın da var olduğu rapor edilmiştir. Bu bitkilerde hücre stoplazmasından fazla tuzun etkin bir sekilde atılması yanında, tuzun vokuoller aracılığı ile hücreden etkin bir şekilde ayrıştırılması mümkün olabilmektedir. Bu nedenle halofit bitkiler diğer bitki türleri ile kıyaslandığında tuzlu topraklarda daha iyi büyüme gösterip, daha uzun bir yaşam sürdürebilmektedir. Farklı bitki türlerinde tuza toleransın çok sayıda gen ve transkripsiyon faktörü tarafından kontrol edildiği belirlenmiştir. Fonsiyonel siniflandırma bakımından söz konusu gen ve transkripsiyon faktörleri 4 temel grup altında incelenmektedir: (I) iyon taşınması veya iyon 
dengesini sağlayan genler (homeostasis) (örneğin, SOS, NHX1, HKT1 and H+-ATPase genlerinde olduğu gibi), (II) yaşlılık ile ilişkili genler (örneğin, $S A G$ ), (III) moleküler şaperon (refakatçi) proteinler (örneğin, HSP) ve (IV) dehidrasyonla ilişkili genler (örneğin, DREB) (Bu ve ark., 2015).

Farklı abiyotik stres faktörlerinde olduğu gibi tuz stresinin bitkiler tarafindan tolere edilmesinde fonksiyonel olduğu düşünülen farklı bitkisel mekanizmalardan da bahsedilmektedir. $\mathrm{Bu}$ mekanizmalar başlıca üç ana katagoride siniflandırılabilmektedir: (I) ozmotik tolerans, (II) iyon atılımı ve (III) doku toleransı. Ozmotik tolerans daha ziyade $\mathrm{Na}+$ iyonlarının gövdede birikiminden önceki bir evrede, spesifik olarak uzun mesafeli sinyal iletim mekanizması tarafından kontrol edilen ve sonuçta bitki saplarında büyümenin azaltılması şeklinde kendini gösteren mekanizmadır. İyon atılım mekanizması ise toksik $\mathrm{Na}$ ve CI konsantrasyonlarının yapraklarda birikiminin azaltılmasını kontrol eden mekanizmadır. Son mekanizma olan doku tolerans mekanizması ise tuz stresine maruz kalan bitkilerde görülen dokuya özgü büyüme gerilemesidir. Nitekim tuza tolerans, bazı bitki türlerinde tuzun bitki saplarında birikimi veya sapta tuz birikiminden bağımsız olan birbirinden çok farklı mekanizmalar ile kontrol edilmektedir (Roy ve ark., 2014). Bitki türüne bağlı olmak kaydı ile birkaç dakikadan birkaç gün ve hatta haftaya kadar geçen zaman aralığında bu mekanizmaların deneysel tespiti mümkün olabilmektedir. Ancak, tuz stresine karşı oluşacak hızlı ve ani bitkisel tepkilerin sapta tuz birikim mekanizmasından bağımsız olduğu ortadadır. Tuz stresine karşı oluşan ani tepki mekanizmalarından şimdiye kadar açıklanan en iyi iki mekanizma, yapraklarda sıcaklık artışı ile beraber oluşan stoma kapanması ve sap uzamasının azaltılması mekanizmalarıdır (Sirault ve ark., 2009). $\mathrm{Bu}$ mekanizmaların çalışmasına bağlı olarak ortaya çıkan birincil sonuçlar bitkide yeni yaprak oluşumunun azalması ve bitki sap büyümesinin engellenmesidir. $\mathrm{Bu}$ durum bazı araştırıcılar tarafindan "ozmotik faz" olarak isimlendirilmekle birlikte su potansiyelindeki değişimin sadece tuza bağlanamayacağına dair farklı bilimsel bulgular da bulunmaktadır (Munns ve Passioura, 1984). Bitkilerin tuz stresine karşı olan tepkilerindeki ikinci faz ise tepki zamanı bakımından gün ve haftalar ile ifade edilebilecek büyüme gerilmesidir. İyonik faz olarak ifade edilen bu fazda, tuzun bitki dokularında özellikle de yaşlı yapraklarda birikimine bağlı olarak yapraklarda erken dökülmelere neden olan tepki mekanizmasıdır (Munns ve Tester, 2008).

Baklagil bitkileri genel olarak tuz stresine karşı hassas olarak bilinirler. Örneğin, fiğ bitkisi (Vicia sativa L.), tarımı yapılan diğer kültür bitkilerinde olduğu gibi özellikle çimlenme ve erken fide evrelerinde tuz stesine karşı hassasiyet göstermektedir. Farklı fiğ türlerinde, çimlenme ve çıkış ile erken fide evrelerinde bitkilerin tuz stresine verdikleri tepkiler morfolojik ve bazı fizyolojik parametreler kullanılarak belirlenmiştir. Yaygın fiğ, bezelye ve kolza kullanarak yapılan tuz stresi çalışmasında 45 günlük bitkilere uygulanan $0,50,100$ and $150 \mathrm{mM} \mathrm{NaCl}$ tuz stresinin bitkilerin gelişimini önemli oranda gerilettiği, yaygin fiğ bitkisinin ise 100 $\mathrm{mM}$ NaCl'ün üzerindeki tuz stresinde canlılığını kaybettiği belirlenmiştir (Biligili ve ark., 2011). Tuz ve kuraklık stresinin beraber uygulandığ başka bir çalışmada, yaygın fiğ türünün düşük tuz ve su yetersizliğinden etkilenmediği bildirilmiştir (Orak ve Ateş, 2005). Fiğ türlerinden burçak kullanılarak yapılan tuz stresi çalışmasında, tuz stresinin çimlenme, çıkış ve erken fide evresinde incelenen bitkisel özelliklerde önemli gerilemelere neden olduğu ve bu olumsuz etkinin bitkinin sapcık kısminda köke oranla daha fazla meydana geldiği bildirilmiştir (Çöçü ve Uzun, 2011). Benzer şekilde tüylü fï̆ (Vicia villosa L.) ile yapılan bir çalışmada bitkinin özellikle çimlenme, çıkış ve erken fide döneminde artan tuz stresinden önemli oranda etkilendiği rapor edilmiştir (Lee ve ark., 2014). Koca fiğ (Vicia narbonensis L.) kullanılarak yapılan tuz stesi çalışmasında ise bitkinin tuz stresine oldukça hassas olduğu ve \%2.5'in üzerindeki $\mathrm{NaCI}$ konsanstrasyonuna dayanamadığ belirtilmiştir (Mezni ve ark., 2013). Tuz stresi aynı zamanda baklagillerde nodül sayısı ve fikse edilen azot miktarında önemli gerilemelere neden olmaktadır. Tuz, özellikle köklerde rhizobial koloni oluşumunu ve erken bakteri enfeksiyonu süreçlerini olumsuz yönde etkilemektedir (Zahran, 2001; Zahran ve Sprent, 1986). Gelişim evrelerinde tuz stresine maruz kalan baklagillerde $\mathrm{N}$ fixasyonu, tuz stresine karşı büyük bir duyarlılık göstermektedir (Boukhatem ve ark., 2012; Zahran ve Sprent, 1986). Diğer taraftan $200 \mathrm{mM} \mathrm{NaCI}$ gibi yüksek tuz konsantrasyonlarının kırmızı ve ak üçül (Gravandı, 2013), anadolu üçü̈lü (Ates ve Tekeli, 2007), çilek üçgülü (CAN ve ark., 2013), ak üçgül ve iskenderiye üçülü (Saberi ve ark., 2013), yaygin yonca (Kaplan ve ark., 2015; Zhanwu ve ark., 2011), sarı taş yoncası (Ghaderi-Far ve ark., 2010) ve korunga (Majidi ve ark., 2010) tohumlarının çimlenme ve fidelerinde çok önemli gerilemelere neden olduğu rapor edilmiştir .

Tohum çimlenmesi ve fide gelişim aşamaları bitki yaşaminın en kritik aşamalardan olup bitkisel verimliliği doğrudan etkilemektedir. Yanlış sulama ve yetiştirme teknikleri ile monokültürel uygulamalar kurak ve yarı kurak bölgelerde topraktaki tuz konsantrasyonunun zaman içerisinde artmasına, yeterli önlemlerin alınmaması durumunda ise bu alanların elden çıkmasına neden olmaktadır. Toprak üst tabakasında artan yüksek tuz konsantrasyonu, iyi bir bitki örtüsünün oluşmasını engellemekte, özellikle 
direkt tohum ekimi ile üretilen birçok tarla bitkisinin yetiştiriciliğini sınırlandırarak büyük ekonomik kayılara neden olabilmektedir (Qadir ve ark., 2014). $\mathrm{Bu}$ durum bitkilerin ileriki gelişme dönemlerinde karşılaşacakları biyotik stres etmenlerine karşı hassasiyetlerinin de artmasina neden olmaktadır (Croser ve ark., 2003).

\section{Moleküler Mekanizmalar}

Model ve bazı kültür bitkilerinde, tek bir gende meydana gelen mutasyonlar ile tuza toleransin artırılabildiği bilinmektedir. Buna örnek olarak soya fasulyesi (Abel, 1969; Çelik ve Ünsal, 2013), arpa (Kueh ve Bright, 1982), tütün (Sumaryati ve ark., 1992) ve Arabidopsis (Tsugane ve ark., 1999) gösterilebilir. Bitkilerde tuz stresi varlığında ifade edilebilen çok sayıda gen bulunduğu ve bu genlerin bazılarının tuz, kurak ve soğuk gibi diğer abiyotik stres koşullarında çapraz sinyal iletimi (signaling cross-talk) içerisinde bulundukları, ancak diğer bazı genlerin ise strese özgü ifadeler sergiledikleri bilinmektedir (Seki ve ark., 2001; Seki ve ark., 2002a; Seki ve ark., 2002b; Rabbani ve ark., 2003; Takahashi ve ark., 2004; Jin ve ark., 2010; Bai ve ark., 2013; Tang ve ark., 2013). Ayrica, DNA mikroarray (microarray), EST (Expressed Sequence Tags) teknolojileri sayesinde bitkilerde stres şartlarında ifadeleri artan ya da azalan genlerin neler olduğu tespit edilebilmektedir (Schenk ve ark., 2000; Chen ve ark., 2011; Cho ve ark., 2012; Liu ve ark., 2014; . BLAST (Basic Local Alignment Search Tool) analiz sonuçları tuz stresi de dahil olmak üzere, stresle ilişkili genlere ait sekanslar arasında büyük bir benzerlik (synteny) olduğunu göstermektedir (Maughan ve ark., 2009; Fang ve ark., 2014; Liu ve ark., 2015). Diğer taraftan, abiyotik stres şartlarına karşı toleransın geliştirilmesine yönelik moleküler çalışmalar, stresle ilişkili genlerin ifadelerinin artırılması ve dayanıklı genotiplerin geliştirilmesi üzerine yoğunlaşmıştır. Tütünde yapılan çalışmalar, $p 5 c s$ (Delta1 pyrroline ${ }^{-5}$ carboxylate synthase) geninin tuz stresi altındaki bitkilerde prolin miktarlarında önemli artışlara neden olduğunu ve bu artışın bitkinin tuz stresini daha iyi tolere etmesine yardımcı olduğunu göstermiştir (Kishor ve ark., 1995). Yapılan başka bir çalışmada ise prolin degredasyonunda görev alan ilk enzimin Prolin dehydrogenase (ProDH) enzimi olduğu ve bu genin Arabidopsis bitkisinden elde edilen dehydrogenase (AtProDH) mRNA ile sessizleştirilmesi sonucunda, bitkinin yüksek $\mathrm{NaCl} \quad(600 \mathrm{mM})$ stresine dayanabildiklerini göstermiştir (Nanjo ve ark., 1999a; Nanjo ve ark., 1999b). Bitkilerin farkl stres etmenlerine karşı gösterdikleri tepkileri fizyolojik parametreler kullanarak belirlemek genelde başvurulan yöntemler olmakla birlikte, bu parametrelerin birçoğu farklı stres etmenlerine karşı geliştirilen ortak tepkiler olmaları ve çevresel etmenlerden etkilenmeleri, tolerant bitkilerin belirlenmesinde sorunların yaşanmasına neden olabilmektedir (Annicchiarico ve ark., 2013; Kocabay ve ark., 2013). Bugüne kadar farklı bitkilere ait stresle ilişkili birçok gen izole edilmiş olmasına karşın (Cattivelli ve ark., 2002), bitkilerde kurak ve tuzluluğa karşı verilen tepkinin çok karmaşı olması nedeniyle tüm moleküler tepkilerin kapsamlı olarak anlaşılması ancak yakın zamanda yapılan transkriptome çalışmaları ile mümkün olabilmiştir (Hazen ve ark., 2005; Verslues ve ark., 2006; Verslues ve Juenger, 2011). LEA (late-embryogenesis abundant) ve DREB (dehydration response element binding) gibi tuz ve kuraklık ile birlikte indüklenen transkripsiyon faktörleri ve gen ürünleri, su noksanlığ 1 ve tuz stresine karşı tepkinin oluşmasında önemli rol oynayarak; sinyal iletim yollarını aktive etmekte, hücresel yapıları korumakta ve tuzluluk toleransinin oluşmasını sağlamaktadır (Romo ve ark., 2001). Örneğin, proline biyosentezinde görevli P5CS, (Delta1 pyrroline -5-carboxylate synthase) gibi bazı stresle ilişkili proteinleri kodlayan genlerin transgenik bitkilerdeki ifadelerinin artırılması tuz ve kuraklığa toleransın artmasına neden olmuştur (Kishore ve ark., 1995; Çelik ve Atak, 2012). Ozmotik stres şartlarında serbest prolin birikimi P5CS enzimi sayesinde oluşurken, bu genin antisensinin aktarıldığı bitkilerde ozmotik strese karşı aşırı duyarlılığın geliştiği rapor edilmiştir (Nanjo ve ark., 1999c). Bu bitkilerde prolin azlığ $\breve{1}_{1}$ spesifik olarak yapisal proteinleri etkilemekte, prolinin stres altındaki bitkilerde ozmotik dengeleyici olarak görev yaptığını göstermektedir (Sakamoto ve Murata, 2002; Çelik ve Ünsal, 2013). Bitkilerde tuz stresine karşı toleransın oluşmasında görev alan en önemli spesifik gen ailesi ise SOS (salt overly sensitive)'tur. $S O S$ gen ailesi üç farklı gen yapısından oluşmakta olup bu genlerin sitozoldaki $\mathrm{Na}^{+}$iyonunun hücre dışına akışının kontrol edilerek bitkilerde tuz stresinin kontrolünde önemli rol oynadığ bildirilmiştir (Zhu, 2000; Zhu, 2001; Zhu, 2002; Zhu, 2003). SOS genlerinden $S O S 1$ bitkilerde tuz stresinin kontrol edilmesinde en önemli role sahip olduğu, bu genin ifadesinde meydana gelen artış miktarına parallel olarak bitkilerde tuz stresinin de $\operatorname{arttığ~ve~}$ sekans dizilerinin bitkilerde büyük oranda benzer olduğu rapor edilmiştir (Shi ve ark., 2003; Munns, 2005; Liu ve ark., 2015). Ayrıca, SOS genlerine ait düzenleme mekanizmasının baklagil ve buğdaygil bitkilerinde korunmuş mekanizmlar olduğu bildirilmiştir (Ismail ve ark., 2014) Diğer taraftan çeltikte yapılan çalışmalar $D R E B 1 / C B F, D R E B 2$ ve $A R E B / A B F$ genlerinin abiyotik stres faktörlerine karşı tepkilerin oluşmasında önemli roller üstlendiği gösterilmiştir (Mizoi ve ark., 2012; Fujita ve ark., 2013). AtWRKY8, OsNAC5 ve ZFP179 gibi transkripsiyon faktörlerinin diğer abiyotik stres faktörlerine karşı hücresel tepkilerin oluşmasında hücredeki prolin, şeker ve LEA proteinlerinin oluşmasında etkili oldukları ve tuz stresi varlığında da 
ifade seviyelerini önemli oranda artırdıkları tespit edilmiştir (Song ve ark., 2011; Hu ve ark., 2013). Tuz stresi karşısında gen ifadesi azalan ya da artan çok sayıda genin var olmasına karşın, bunlar genelde 3 kategoride sinıflandırılmaktadır: (I) iyon taşınması veya hücre içi iyon dengesinin sağlanmasında görev alan SOS genleri ve $A t N H X 1$ geni, (II) hücre yaşlanması ilişkili $S A G$ genleri (senescence-associated genes) ve $H S P$ gibi moleküler çaporon genleri ve (III) DREB gibi dehidrasyon ilişkili transkripsiyon faktörleri. Bunlar içerisinde en önemli gen ailesini iyon transportu ile ilişkili SOS genleri oluşturmaktadır (Chakraborty ve ark., 2012). Ayrıca, halofit bir bitki türü olan Spartina alterniflora'da tuz stresi karşısında gen ifade seviyesi en çok artan $b Z I P, W R K Y, A P 2, N A$ ve, $C 2 H 2$ zinc finger gibi 10 gen tespit edilmiştir (Schmidt ve ark., 2013; Schmidt ve ark., 2014). Tuz stresine yönelik çok sayıda spesifik genin tespit edilmesi bu genlerin tuza tolerant bitkilerin geliştirilmesinde farklı amaçlarla doğrudan kullanılabileceğini göstermektedir. Bu nedenle son yıllarda, tuz stresinden etkilenen ve sekansı bilinen genlerin ifade düzeylerinin gerçek zamanlı PCR (qRTPCR) kullanarak tespit edilmesi ve bu yolla tuz stresine tolerant ya da hassas bitki genotiplerinin güvenilir şekilde belirlenmesi mümkün olabilmektedir (Torres ve ark., 2006; Çelik ve Atak, 2012; Çelik ve Ünsal, 2013).

\section{SONUÇ}

Gelecekte tarımsal üretimin karşı karşıya kaldığı biyotik stres faktörler yanında abiyotik stres faktörlerinin de dikkate alınarak, stres faktörlerini tek ya da kombine halde daha iyi tolere edebilen yeni bitki çeşitlerinin geliştirilmesi gerekmektedir. Bitkiler üzerindeki etki mekanizmaları göz önüne alındığında tuz stresi, bazı durumlarda kuraklık ile birlikte, bazı durumlarda ise tek başına ele alınması gereken, bitki büyüme ve gelişmesi ile verimini doğrudan etkileyen en önemli abiyotik stres faktörlerinin başında gelmektedir. Bu stres faktörüne karşı tolerant yeni bitki çeşitlerinin geliştirilmesi ve buna yönelik ıslah programlarının başlatılması oldukça önemlidir. Ülkemizin kendine özgü toprak ve iklim şartları göz önüne alınarak bazı bölgelerimizde ortaya çıkan tuzluluk sorunun çözümüne yönelik pratik uygulamalarm hayata geçirilmesi ve henüz sorun yaşanmayan alanlarda çoraklaşmanın önüne geçecek önleyici tarımsal uygulamaların planlanması, spesifik olarak tuza tolerant uygun yeni bitki çeşitlerinin geliştirilmesine ve yaygınlaştırılmasına doğrudan bağlı olacaktır.

\section{KAYNAKLAR}

Abel GH 1969. Inheritance of the capacity for chloride inclusion and exclusion by soybeans. Crop Science, 9: 697-698.

Annicchiarico P, Pecetti L, Tava A 2013. Physiological and morphological traits associated with adaptation of lucerne (Medicago sativa) to severely droughtstressed and to irrigated environments. Annals of Applied Biology, 162: 27-40.

Anonim 2005. Çölleşme ile mücadele Türkiye ulusal eylem programı. T.C. Cevre ve Orman Bakanlığ yayınları No: 250, Ankara, ISBN 975-7347-51-5.

Aslam M, Qureshi RH, Ahmed N 1993. A rapid screening technique for salt tolerance in rice (Oryza sativa L.). Plant Soil, 150: 99-107.

Ateş E, Tekeli AS 2007. Salinity tolerance of Persian clover (Trifolium resupinatum var. majus Boiss) lines at germination and seedling stage. World Journal of Agricultural Sciences, 3: 71-79.

Bai X, Liu J, Tang LL, Cai H, Chen M, Ji W, Liu Y, Zhu YM 2013. Overexpression of GsCBRLK from Glycine soja enhances tolerance to salt stress in transgenic alfalfa (Medicago sativa). Functional Plant Biology, 40: 1048-1056.

Bartels D, Sunkar R 2005. Drought and Salt Tolerance in Plants. Critical Reviews in Plant Sciences, 24: 23-58.

Biligili U, Çarpıcı EB, Aşık BB, Çelik N 2011. Root and shoot response of common vetch (Vicia sativa L.), forage pea (Pisum sativum L.) and canola (Brassica napus L.) to salt stress during early seedling growth stages. Turkish Journal of Field Crops, 16: 33-38.

Boukhatem ZF, Domergue O, Bekki A, Merabet C, Sekkour S, Bouazza F, Duponnois R, de Lajudie P, Galiana A 2012. Symbiotic characterization and diversity of rhizobia associated with native and introduced acacias in arid and semi-arid regions in Algeria. FEMS Microbiol Ecology, 80: 534-47.

Bu Y, Kou J, Sun, B, Takano T, Liu S 2015. Adverse effect of urease on salt stress during seed germination in Arabidopsis thaliana. FEBS Letter, 589: 1308-13.

Can E, Arslan M, Sener O, Daghan H 2013. Response of strawberry clover (Trifolium fragiferum L.) to salinity stress. Research on Crops, 14: 576-584.

Cattivelli L, Baldi P, Crosatti C, Di Fonzo N, Faccioli P, Grossi M, Mastrangelo AM, Pecchioni N, Stanca AM 2002. Chromosome regions and stress-related sequences involved in resistance to abiotic stress in Triticeae. Plant Molecular Biology, 48: 649-665.

Chakraborty K, Sairam RK, Bhattacharya RC 2012. Differential expression of salt overly sensitive pathway genes determines salinity stress tolerance in Brassica genotypes. Plant Physiology Biochemistry, 51: 90-101.

Chazen O, Hartung W, Neumann PM 1995. The different effects of PEG 6000 and $\mathrm{NaCI}$ on leaf development are associated with differential inhibition of root water transport. Plant Cell and Environment, 18: 727-735.

Chen H, Zhang B, Hicks LM, Xiong L 2011. A nucleotide metabolite controls stress-responsive gene expression and plant development. PLoS One, 6: e26661.

Cho YH, Hong JW, Kim EC, Yoo SD 2012. Regulatory functions of SnRK1 in stress-responsive gene expression and in plant growth and development. 
Plant Physiology, 158: 1955-64.

Cramer GR, Alberico GJ, Schmidt C 1994. Leaf Expansion Limits Dry Matter Accumulation of Saltstressed Maize. Australian Journal of Plant Physiology, 21: 663-674.

Croser JS, Clarke HJ, Siddique KHM, Khan TN 2003. Low-temperature stress: Implications for chickpea (Cicer arietinum L.) improvement. Critical Review in Plant Science, 22: 185-219.

Çelik Ö, Atak Ç 2012. Evalutation of proline accumulation and Delta1 pyrroline -5-carboxylate synthase (P5CS) gene expression during salinity stress in two soybean (Glycine max L. Merr) varieties. Polish Journal of Environmental. Studies, 21: 559564.

Çelik Ö, Ünsal SG 2013. Expression analysis of proline metabolism-related genes in salt-tolerant soybean mutant plants. Plant Omics Journal, 6(5): 364-370.

Çöçü S, Uzun O 2011. Germination, seedling growth and ion accumulation of bitter vetch (Vicia ervilia (L.) Willd. ) lines under $\mathrm{NaCl}$ stress. African Journal of Biotechnology, 10: 15869-15874.

Fang J, Han X, Xie L, Liu M, Qiao G, Jiang J, Zhuo R 2014. Isolation of salt stress-related genes from Aspergillus glaucus CCHA by random overexpression in Escherichia coli. Scientific WorldJ ournal, 2014: 620959.

Fujita Y, Yoshida T, Yamaguchi-Shinozaki K 2013. Pivotal role of the AREB/ABF-SnRK2 pathway in ABRE-mediated transcription in response to osmotic stress in plants. Physiologia Plantarum, 147: 15-27.

Ghaderi-Far F, Gherekhlo J, Alimagham M 2010. Influence of environmental factors on seed germination and seedling emergence of yellow sweet clover (Melilotus officinalis). Planta Daninha, 28: 463469.

Gravandi S 2013. The examination of different $\mathrm{NaCl}$ concentrations on germination, radicle length and plumule length on three cultivars of clover. Annals of Biological Research, 4: 200-203.

Hasegawa PM, Bressan RA, Zhu JK, Bohnert HJ 2000. Plant Cellular and Molecular Responses to High Salinity. Annual Review Plant Physiology and Plant Molecular Biology, 51: 463-499.

Hazen SP, Pathan MS. Sanchez A, Baxter I, Dunn M, Estes B, Chang HS, Zhu T, Kreps JA, Nguyen HT 2005. Expression profiling of rice segregating for drought tolerance QTLs using a rice genome array. Functional and Integrative Genomics, 5: 104-116.

Hu Y, Chen L, Wang H, Zhang L, Wang F, Yu D 2013. Arabidopsis transcription factor WRKY8 functions antagonistically with its interacting partner VQ9 to modulate salinity stress tolerance. Plant Journal, 74: 730-45.

Ismail A, Takeda S, Nick P 2014. Life and death under salt stress: same players, different timing? Journal of Experimental Botany, 65:2963-2979.

Jin HC, Sun Y, Yang QC, Chao YH, Kang JM, Jin, H., Li,
Y., Margaret, G. 2010. Screening of genes induced by salt stress from Alfalfa. Molecular Biology Reports, 37, $745-753$.

Kang J, Xie W, Sun Y, Yang Q, Wu M 2010. Identification of genes induced by salt stress from Medicago truncatula L. seedlings. African Journal of Biotechnology, 9: 7589-7594.

Kaplan Ş, Güçlü Ş, Baytekin G, Tiryaki İ 2015. Yonca (Medicago sativa L.) ve çayır üçgülü (Trifolium pratense L.) tohumlarmin tuz ve kuraklık stresine verdikleri tepkilerin belirlenmesi. Türkiye 11. Tarla Bitkileri Kongresi, 7-10 Eylül 2015, Çanakkale.

Kishor KPB, Hong Z, Miao GH, Hu CAA, Verma DPS 1995. Overexpression of D1-pyrroline-5-carboxylate synthetase increase proline production and confers osmotolerance in transgenic plants. Plant Physiology, 108: 1387-1394.

Kishore PBK, Hong Z, Miao G-U, Hu C-A, Verma DPS 1995. Overexpression of D-pyrroline-5-carboxylase synthetase increases proline production and confers osmotolerance in transgenic plants. Plant Physiology, 108: 1387-1394.

Kocabay O, Emregul E, Aydin SS, Aras S 2013. Detection of superoxide radicals in tomato plants exposed to salinity, drought, cold and heavy metal stress using CMC-G-SOD biosensor. Artif Cells Nanomed Biotechnology, 41: 352-8.

Kueh JSH, Bright SWJ 1982. Biochemical and genetic analysis of three proline accumulating barley mutants. Plant Science Letters, 27: 233-224.

Lee S-B, Kim J-H, Yun J-C 2014. Availability of hairy vetch (Vicia villosa Roth) as leguminous green manure crops for organic rice cultivation in reclaimed saline land. in: Proceedings of the 4th ISOFAR Scientific Conference. Istanbul, Turkey, pp. eprint ID 23671.

Liu M, Qiao G, Jiang J, Han X, Sang J, Zhuo R 2014. Identification and expression analysis of saltresponsive genes using a comparative microarray approach in Salix matsudana. Molecular Biology Reports, 41: 6555-68.

Liu M, Wang T-Z, Zhang W-H 2015. Sodium extrusion associated with enhanced expression of SOS1underlies different salt tolerance between Medicago falcata and Medicago truncatula seedlings. Environmental and Experimental Botany, 110: 46-55.

Majidi MM, Jazayeri MR, Mohammadinejad G 2010. Effect of salt stress on germination characters and some ions accumulation of sainfoin (Onobrychis viciifolia Scop.) genotypes. Iranian Journal of Rangelands and Forests Plant Breeding Research, 17: 256-269.

Maughan PJ, Turner TB, Coleman CE, Elzinga DB, Jellen EN, Morales JA, Udall JA, Fairbanks DJ, Bonifacio A 2009. Characterization of Salt Overly Sensitive 1 (SOS1) gene homoeologs in quinoa (Chenopodium quinoa Willd.). Genome, 52: 647-57.

Mezni, M., Ghnaya-Chakroun, A.B., Haffani, S. 2013. 
Growth and water status in narbonne vetch (Vicia narbonensis L.) under salt stres. Journal of Agriculture and Veterinary Science, 3(3): 2319-2372.

Mizoi J, Shinozaki K, Yamaguchi-Shinozaki K 2012. AP2/ERF family transcription factors in plant abiotic stress responses. Biochimica Biophysica Acta, 1819: 86-96.

Mladenova YI 1990. Influence of salt stress on primary metabolism of Zea mays L. seedlings of model genotypes. Plant and Soil, 123: 217-222.

Munns R 2005. Genes and salt tolerance: bringing them together. New Phytologist, 167(3): 645-63.

Munns R, Gilliham M 2015. Salinity tolerance of crops what is the cost? New Phytologist, 208: 668-73.

Munns R, Passioura JB 1984. Hydraulic resistance of plants. 3. Effects of $\mathrm{NaCl}$ in barley and lupin. Australian Journal of Plant Physiology, 11: 351-359.

Munns, R., Tester, M. 2008. Mechanisms of salinity tolerance. Annu Review of Plant Biology, 59: 651-81.

Nanjo T, Kobayashi M, Yoshiba Y, Kakubari Y, Yamaguchi-Shinozaki K, Shinozaki K 1999a. Antisense suppression of proline degradation improves tolerance to freezing and salinity in Arabidopsis thaliana. FEBS Letters, 461: 205-210.

Nanjo T, Kobayashi M, Yoshiba Y, Sanada Y, Wada K, Tsukaya H, Kakubari Y, Yamaguchi-Shinozaki K, Shinozaki K 1999c. Biological functions of proline in morphogenesis and osmotolerance revealed in antisense transgenic Arabidopsis thaliana. Plant Journal, 18: 185-193.

Onaga G, Wydra K 2016. Advances in Plant Tolerance to Abiotic Stresses. (Plant Genomics, InTech: Ed. Abdurakhmonov, D.I.Y.) 167-228.

Orak A, Ateş E 2005 Resistance to salinity stress and available water levels at the seedling stage of the common vetch (Vicia sativa L.). Plant Soil and Environment, 51: 51-56.

Ouyang SQ, Liu YF, Liu P, Lei G, He SJ, Ma B, Zhang WK, Zhang JS, Chen SY 2010. Receptor-like kinase OsSIK1 improves drought and salt stress tolerance in rice (Oryza sativa) plants. Plant Journal, 62: 316-29.

Parida AK, Das AB 2005. Salt tolerance and salinity effects on plants: a review. Ecotoxicol and Environ Safety, 60: 324-49.

Pastori GM, Foyer CH 2002. Common components, networks, and pathways of cross-tolerance to stress. The central role of "redox" and abscisic acid-mediated controls. Plant Physiology, 129: 460-468.

Platten JD, Cotsaftis O, Berthomieu P, Bohnert H, Davenport RJ, Fairbairn DJ, Horie T, Leigh RA, Lin HX, Luan S, Maser P, Pantoja O, Rodriguez-Navarro A, Schachtman DP, Schroeder JI, Sentenac H, Uozumi N, Very AA, Zhu JK, Dennis ES, Tester M 2006. Nomenclature for HKT transporters, key determinants of plant salinity tolerance. Trends in Plant Science, 11: 372-4.

Platten JD, Egdane JA, Ismail AM 2013. Salinity tolerance, $\mathrm{Na}+$ exclusion and allele mining of HKT1;5 in Oryza sativa and O. glaberrima: many sources, many genes, one mechanism? BMC Plant Biology, 13: 32.

Qadir M, Quillerou E, Nangia V, Murtaza G, Singh M, Thomas RJ, Drechsel P, Noble AD 2014.Economics of salt-induced land degradation and restoration. Natural Resources Forum 38: 282-295.

Rabbani MA, Maruyama K, Abe H, Khan MA, Katsura K, Ito Y, Yoshiwara K, Seki M, Shinozaki K, Yamaguchi-Shinozaki K 2003. Monitoring expression profiles of rice genes under cold, drought, and highsalinity stresses and abscisic acid application using cDNA microarray and RNA gel-blot analyses. Plant Physiology, 133: 1755-67.

Romo S, Labrador E, Dopico B 2001. Water stressregulated gene expression in Cicer arietinum seedlings and plants. Plant Physiology and Biochemistry, 39: 1017-1026.

Roy SJ, Negrao S, Tester M 2014. Salt resistant crop plants. Current Opinion in Biotechnology, 26: 115-24.

Saberi M, Davari A, Pouzesh H, Shahriari A 2013. Effect of different levels of salinity and temperature on seeds germination characteristics of two range Species under laboratory condition. International Journal of Agriculture and Crop Science, 5: 1553-1559.

Sakamoto A, Murata N 2002. The role of glycine betaine in the protection of plants from stress: clues from transgenic plants. Plant Cell and Environment, 25: 163-171.

Schenk PM, Kazan K, Wilson I, Anderson JP, Richmond T, Somerville SC, Manners JM 2000. Coordinated plant defense responses in Arabidopsis revealed by microarray analysis. Proceedings of the National Academy of Sciences of the United States, 97: 1165511660.

Schmidt R, Mieulet D, Hubberten HM, Obata T, Hoefgen R, Fernie AR, Fisahn J, San Segundo B, Guiderdoni E, Schippers JH, Mueller-Roeber B 2013. Saltresponsive ERF1 regulates reactive oxygen speciesdependent signaling during the initial response to salt stress in rice. Plant Cell, 25: 2115-31.

Schmidt R, Schippers JH, Mieulet D, Watanabe M, Hoefgen R, Guiderdoni E, Mueller-Roeber B 2014. SALT-RESPONSIVE $E R F 1$ is a negative regulator of grain filling and gibberellin-mediated seedling establishment in rice. Molecular Plant, 7: 404-21.

Seki M, Ishida J, Narusaka M, Fujita M, Nanjo T, Umezawa T, Kamiya A, Nakajima M, Enju A, Sakurai T, Satou M, Akiyama K, Yamaguchi-Shinozaki K, Carninci P, Kawai J, Hayashizaki Y, Shinozaki K 2002a. Monitoring the expression pattern of around 7,000 Arabidopsis genes under ABA treatments using a full-length cDNA microarray. Functional and Integrative Genomics, 2: 282-91.

Seki M, Narusaka M, Abe H, Kasuga M, YamaguchiShinozaki K, Carninci P, Hayashizaki Y, Shinozaki K 2001. Monitoring the expression pattern of 1300 Arabidopsis genes under drought and cold stresses by 
using a full-length cDNA microarray. Plant Cell, 13: 61-72.

Seki M, Narusaka M, Ishida J, Nanjo T, Fujita M, Oono Y, Kamiya A, Nakajima M, Enju A, Sakurai T, Satou M, Akiyama K, Taji T, Yamaguchi-Shinozaki K, Carninci P, Kawai J, Hayashizaki Y, Shinozaki K 2002b. Monitoring the expression profiles of 7000 Arabidopsis genes under drought, cold and highsalinity stresses using a full-length cDNA microarray. Plant Journal, 31: 279-92.

Shavrukov Y 2013. Salt stress or salt shock: which genes are we studying? Journal of Experimental Botany, 64(1): 119-27.

Shi H, Lee BH, Wu SJ, Zhu JK 2003. Overexpression of a plasma membrane $\mathrm{Na}+\mathrm{H}+$ antiporter gene improves salt tolerance in Arabidopsis thaliana. Nature Biotechnology, 21: 81-5.

Sirault XRR, James RA, Furbank RT 2009. A new screening method for osmotic component of salinity tolerance in cereals using infrared thermography. Functional Plant Biology, 36: 970-977.

Song S-Y, Chen Y, Chen J, Dai X-Y, Zhang W-H 2011. Physiological mechanisms underlying OsNAC5dependent tolerance of rice plants to abiotic stress. Planta, 234: 331-345.

Sumaryati S, Negrutiu I, Jacobs M 1992. Characterization and regeneration of salt- and waterstress mutants from protoplast culture of Nicotiana plumbaginifolia (Viviani). Theoretical and Applied Genetetics, 83: 613-619.

Takahashi S, Seki M, Ishida J, Satou M, Sakurai T, Narusaka M, Kamiya A, Nakajima M, Enju A, Akiyama K, Yamaguchi-Shinozaki K, Shinozaki K 2004. Monitoring the expression profiles of genes induced by hyperosmotic, high salinity, and oxidative stress and abscisic acid treatment in Arabidopsis cell culture using a full-length cDNA microarray. Plant Molecular Biology, 56: 29-55.

Tang LL, Cai H, Ji W, Luo X, Wang ZY, Wu J, Wang XD, Cui L, Wang Y, Zhu YM, Bai X 2013. Overexpression of GsZFP1 enhances salt and drought tolerance in transgenic alfalfa (Medicago sativa L.). Plant Physiology and Biochemistry, 71: 22-30.

Temel S, Şimşek U 2011. Iğdır Ovası Toprakların Çoraklaşma Süreci ve Çözüm Önerileri. Alınteri, 21(B): 53-59.

Torres GAM, Pflieger S, Corre-Menguy F, Mazubert C, Hartmann C, Lelandais-Briere C 2006. Identification of novel drought-related mRNAs in common bean roots by differential display RT-PCR. Plant Science,
171: 300-307.

Tsugane K, Kobayashi K, Niwa Y, Ohba Y, Wada K, Kobayashi MH 1999. A recessive Arabidopsis mutant that grows photoautotrophically under salt stress shows enhanced active oxygen detoxification. Plant Cell, 11: 1195-1206.

Verslues PE, Agarwal M, Katiyar-Agarwal S, Zhu J, Zhu JK 2006. Methods and concepts in quantifying resistance to drought, salt and freezing, abiotic stresses that affect plant water status. Plant Journal, 46(6): 1092-1092.

Verslues PE, Juenger TE 2011. Drought, metabolites, and Arabidopsis natural variation: a promising combination for understanding adaptation to waterlimited environments. Current Opinion in Plant Biology, 14: 240-245.

Volkov V 2015. Salinity tolerance in plants. Quantitative approach to ion transport starting from halophytes and stepping to genetic and protein engineering for manipulating ion fluxes. Frontiers in Plant Science, 6: 873.

Volkov V, Amtmann A 2006. Thellungiella halophila, a salt-tolerant relative of Arabidopsis thaliana, has specific root ion-channel features supporting $\mathrm{K}+/ \mathrm{Na}+$ homeostasis under salinity stress. Plant Journal, 48: $342-53$

Wu SJ, Ding L, Zhu JK 1996 SOS1, a Genetic Locus Essential for Salt Tolerance and Potassium Acquisition. The Plant Cell, 8: 617-627.

Zahran HH 2001. Rhizobia from wild legumes: diversity, taxonomy, ecology, nitrogen fixation and biotechnology. Journal of Biotechnology, 91: 143-53.

Zahran, HH, Sprent JI 1986. Effects of sodium chloride and polyethylene glycol on root-hair infection and nodulation of Vicia faba L. plants by Rhizobium leguminosarum. Planta, 167: 303-9.

Zhanwu G, Hui Z, Jicai G, Chunwu Y, Chunsheng M, Deli W 2011. Germination responses of Alfalfa (Medicago sativa L.) seeds to various salt-alkaline mixed stress. African Journal of Agricultural Research, 6: 3793-3803.

Zhu JK 2000. Genetic analysis of plant salt tolerance using Arabidopsis. Plant Physiology, 124(3): 941-8.

Zhu JK 2001. Plant salt tolerance. Trends in Plant Science, 6: 66-71.

Zhu JK 2003. Regulation of ion homeostasis under salt stress. Current Opinion in Plant Biology, 6, 441-445.

Zhu JK 2002. Salt and drought stress signal transduction in plants. Annual Review of Plant Biology, 53: 247-73. 